\title{
Impact of EGFR and EGFR ligand expression on treatment response in patients with metastatic colorectal cancer
}

\author{
FEE KLUPP $^{1}$, MALTE SASS $^{2}$, FRANK BERGMANN $^{3}$, ELIAS KHAJEH $^{1}$, OMID GHAMARNEJAD $^{1}$, \\ MATTHIAS HASSENPFLUG ${ }^{1}$, ARIANEB MEHRABI ${ }^{1}$ and YAKUP KULU ${ }^{1}$ \\ ${ }^{1}$ Department of General, Visceral and Transplantation Surgery, University of Heidelberg, D-69120 Heidelberg; \\ ${ }^{2}$ Department of Otorhinolaryngology, Head and Neck Surgery, Asklepios Hospital, D-21075 Hamburg; \\ ${ }^{3}$ Institute of Pathology, University of Heidelberg, D-69120 Heidelberg, Germany
}

Received January 1, 2021; Accepted March 16, 2021

DOI: 10.3892/ol.2021.12709

\begin{abstract}
Up to 50\% of patients with colorectal cancer (CRC) have either synchronous or metachronous hepatic metastases in the course of their disease. Patients with metastatic CRC (mCRC) whose tumors express wild-type KRAS benefit from treatment with monoclonal antibodies (such as cetuximab or panitumumab) that target the epidermal growth factor receptor (EGFR). However, the therapeutic response to these antibodies is variable, and further predictive models are required. The present study examined whether expression of different EGFRs or their ligands in tumors was associated with the response to cetuximab treatment. Tumor tissues, collected during liver resection in 28 patients with $\mathrm{mCRC}$, were analyzed. The protein expression levels of EGFR/ErbB1, ErbB2, ErbB3 and the EGFR ligands heregulin and amphiregulin were determined using Luminex $200^{\circledR}$ and enzyme-linked immunosorbent assays. Computed tomography or magnetic resonance imaging was performed 4 weeks before and 6-8 weeks after treatment with cetuximab. Response to treatment was assessed using the response evaluation criteria for solid tumors (RECIST). The association between the protein expression levels of different EGFRs and their ligands with RECIST criteria was then analyzed to determine whether these protein levels could predict the treatment response to cetuximab. A total of 12 patients exhibited a partial response, 9 exhibited stable disease and 7 exhibited progressive disease after cetuximab therapy according to RECIST. The expression levels of EGFRs (EGFR/ErbB1, ErbB2 and ErbB3) and their ligands (heregulin and amphiregulin) were not significantly
\end{abstract}

Correspondence to: Professor Yakup Kulu, Department of General, Visceral and Transplantation Surgery, University of Heidelberg, Im Neuenheimer Feld 110, D-69120 Heidelberg, Germany

E-mail: yakup.kulu@med.uni-heidelberg.de

Key words: epidermal growth factor, epidermal growth factor receptor, epidermal growth factor receptor ligands, cetuximab, colorectal cancer, liver metastases, prognosis, response associated with the response to cetuximab therapy. Therefore, the present study indicated that EGFR or EGFR ligand expression did not predict treatment response in patients with CRC with liver metastases following cetuximab therapy.

\section{Introduction}

Colorectal cancer (CRC) is one of the most common types of cancer worldwide, with up to $50 \%$ of patients developing either synchronous or metachronous liver metastases (1). Approximately $50 \%$ of the metastasized CRCs have mutations in KRAS and NRAS (2). Patients with distant metastases can be treated with combination chemotherapy, such as folinic acid, 5-FU and oxaliplatin (FOLFOX) or folinic acid, 5-FU and irinotecan (FOLFIRI). Treatment of metastatic CRC (mCRC) is influenced by a variety of variables like tumor side, microsatellite status and genetic alterations (3). In addition, depending on the tumor's mutational status, epidermal growth factor receptor (EGFR) or vascular endothelial growth factor (VEGF) inhibitors can reduce disease progression $(4,5)$. Bevacizumab represents an anti-angiogenic recombinant humanized monoclonal antibody against VEGF-A (6). It induces vascular regression leading to intratumoral hypoxia (7). Its usage is approved for $\mathrm{mCRC}$ patients as first and second line therapy (8). Moreover, an improved outcome in mCRC patients has been demonstrated (9).

The EGFR family comprises different receptor isoforms, including EGFR/ErbB1, ErbB2/Her2, ErbB3/Her3, and ErbB4/Her4 (10). EGFR ligands, such as EGF, heregulin, amphiregulin, and TGF- $\alpha$, bind to EGFR and activate downstream signaling pathways, including the phosphatidylinositol 3-kinase/AKT (PI3K/AKT), RAS/RAF mitogen-activated protein kinase, extracellular signal regulated kinase, and Janus kinase/signal transducers and activators of transcription (JAK/STAT) pathways $(11,12)$. Over-activation of EGFR and its family members promote cell proliferation, transformation and metastasis, and inhibit apoptosis; therefore, anti-EGFR monoclonal antibodies like cetuximab or panitumumab have been used to reduce the metastatic potential of $(4,12,13)$. However, only patients whose tumors express wild-type KRAS benefit from anti-EGFR therapy (14); tumors with de novo mutations in exons 2, 3 and 4 of the KRAS gene acquire 
resistance to cetuximab (15-17). The BOND-2 study showed that the objective therapy response rate is $11 \%$ for cetuximab alone and $22 \%$ for cetuximab combined with other chemotherapy regimens $(18,19)$.

Reliable identification of therapeutic responders and non-responders is of utmost importance for treatment success. Until now, high response rates to cetuximab have only been described in patients with chemorefractory mCRC with overexpression of epiregulin and amphiregulin in primary colorectal cancer tissue (20). Biomarkers that can predict therapeutic success and response would help us to identify which patients with mCRC would benefit from anti-EGFR treatment. In this study, we examined whether differences in EGFR and EGFR ligand protein expression in colorectal cancer liver metastases correlate with the response to cetuximab therapy.

\section{Materials and methods}

Patientcharacteristicsanddatacollection. Twenty-eightpatients who underwent liver resection for metastasized colorectal cancer between 2005 and 2009 were included in this study. Tissues collected from liver metastases during liver resection were stored at $-80^{\circ} \mathrm{C}$ for further use. The study was approved by the Ethics Committee of the University of Heidelberg (S-168/2008) and written informed consent was obtained from each patient. Inclusion criteria were: age $>18$ years, liver metastases due to colorectal cancer, postoperative cetuximab treatment, and computed tomography (CT) or magnetic resonance imaging (MRI) scans prior to and after cetuximab treatment. All patients underwent liver resection and received cetuximab additionally to a combination chemotherapy regime afterwards. None of the patients received cetuximab as an induction therapy before surgery. Patient information, including diagnosis, age, sex, tumor location, primary TNM classification, tumor grading, resection margin status, KRAS mutational status, chemotherapy, CT/MRI based response according to RECIST criteria, and overall survival (time from diagnosis to death or last follow-up) was obtained for all patients. Every patient received a CT or MRI scan $<4$ weeks before and 6-8 weeks after cetuximab therapy. All patients who were included in the study had target lesions. We used the liver metastases as target lesions to evaluate the efficacy of cetuximab. According to RECIST criteria two liver metastases or one - if only a single liver metastasis existed - were measured and the sum of the largest diameters was used as reference value. Single metastasis had a diameter of $\geq 10 \mathrm{~mm}$. For the evaluation of the effect of cetuximab therapy metastases were measured 6-8 weeks after cetuximab therapy. Therefore, again the sum of the largest diameter was calculated. If a metastasis was not detectable anymore or to small it was calculated with $5 \mathrm{~mm}$ generalized. If metastases were confluent and therefore not delimitable anymore, the vector of the largest diameter was taken for calculation. Compared with the reference measurement before cetuximab treatment the following RECIST criteria were used and patients were divided into three groups: partial response (PR): sum of the largest diameters $\geq 30 \%$ less than the reference; progressive disease (PD): sum of the largest diameter $\geq 20 \%$ larger than the reference, increase of the sum of $\geq 5 \mathrm{~mm}$ and/or new lesions; stable disease (SD): neither response nor progressive disease criteria fulfilled (21). RECIST criteria were measured by spiral CT or MRI with maximum 5-mm sections in our Department of Radiology. RECIST criteria were assessed using the Picture Archiving and Communication System (GE Healthcare). Two CT scans were evaluated for each patient, one before and one after cetuximab therapy. Patients underwent the same type of scan (either CT or MRI) before and after cetuximab therapy for better comparison.

Histopathological assessment. Four-micron sections were cut from formalin-fixed paraffin-embedded tissue samples. Sections were stained with hematoxylin-eosin to evaluate sample quality before further use. Tumor tissue samples were evaluated by a board-certified pathologist from the Institute of Pathology, University of Heidelberg, Heidelberg, Germany.

Tissue preparation. Cells were pulverized using the Covaris CryoPrep $^{\text {TM }}$ system (KBiosciences) and tissue was lysed using a cell lysis buffer kit (Merrimack Pharmaceuticals, Inc.) according to the manufacturer's protocol. Total protein concentration was measured using the Pierce ${ }^{\circledR}$ BCA Protein Assay Kit (Thermo Fisher Scientific Inc.) and Infinite $200^{\circledR}$ PRO Reader (Tecan Group Ltd.). Data were analyzed using Magellan $^{\mathrm{TM}}$ Data Analysis Software (Tecan Group Ltd.). For each sample, $0.5 \mu \mathrm{g} / \mu \mathrm{l}$ total protein was used in the assays.

Luminex ${ }^{\circledR}$ based multiplex assay and protein enzyme-linked immunosorbent assay (ELISA). Tissue lysates were processed using Procarta ${ }^{\mathrm{TM}}$ Transcription Factor Assay Kits (Panomics/Affymetrix Inc.) according to the manufacturer's protocol. The Procarta ${ }^{\mathrm{TM}}$ Transcription Factor Assay Kit was used to analyze EGFR/ErB1, ErbB2, ErbB3, and heregulin expression on a Luminex ${ }^{\circledR} 200^{\mathrm{TM}}$ reader (Luminex ${ }^{\circledR}$ Corporation). Amphiregulin (R\&D Systems) protein concentration was measured by ELISA using a Tecan Infinite M200 plate reader (Tecan $\mathrm{GmbH}$ ).

Statistical analysis. Statistical analyses were conducted with Excel 2010 (Microsoft Corporation) and SPSS version 22 (SPSS, IBM Corporation). The Kruskal-Wallis test was used to determine differences in EGFR and EGFR ligand expression between patients with progressive disease, partial response, or stable disease. Expression data are presented as medians with interquartile ranges. Pearsons chi-square test was performed for evaluation of RESCIST criteria vs. KRAS status. Survival analysis was performed with Kaplan-Meier method. Statistical differences between subgroups were analysed using log-rank-test. A P-value $<0.05$ indicated statistical significance.

\section{Results}

Patient characteristics. Twenty-eight patients were included in this study. Each patient underwent liver resection to remove colorectal cancer metastases. Mean age at the time of operation was 52 years. All patients underwent tumor board evaluation for interdisciplinary discussion of further treatment. Twenty patients revealed synchronous liver metastases, 8 patients metachronous liver metastases. Two patients 
Table I. Clinicopathological characteristics in patients with metastatic colorectal cancer $(n=28)$.

\begin{tabular}{|c|c|}
\hline Patient characteristics & Value \\
\hline Mean age $\pm \mathrm{SD}$, years & $52.3 \pm 10.6$ \\
\hline \multicolumn{2}{|l|}{ Sex, n (\%) } \\
\hline Female & $7(25.0)$ \\
\hline Male & $21(75.0)$ \\
\hline \multicolumn{2}{|l|}{ Location of tumor, n (\%) } \\
\hline Colon & $16(57.1)$ \\
\hline Rectum & $12(42.9)$ \\
\hline \multicolumn{2}{|l|}{ Primary T classification, n (\%) } \\
\hline pT2 & $1 \quad(3.6)$ \\
\hline pT3 & $21(75.0)$ \\
\hline pT4 & $6(21.4)$ \\
\hline \multicolumn{2}{|l|}{ Primary N classification, n (\%) } \\
\hline pNO & 1 (3.6) \\
\hline $\mathrm{pN} 1$ & $7(25.0)$ \\
\hline $\mathrm{pN} 2$ & $20(71.4)$ \\
\hline \multicolumn{2}{|l|}{ Primary M classification, n (\%) } \\
\hline pM0 & $4(14.3)$ \\
\hline pM1 & $24(85.7)$ \\
\hline \multicolumn{2}{|l|}{ Primary R status, n (\%) } \\
\hline R0 & $24(85.7)$ \\
\hline $\mathrm{R} 1$ & $3(10.7)$ \\
\hline $\mathrm{R} 2$ & 1 (3.6) \\
\hline \multicolumn{2}{|l|}{ Primary histopathological grade, n (\%) } \\
\hline $\mathrm{G} 2$ & $15(53.6)$ \\
\hline G3 & $12(42.8)$ \\
\hline NA & $1 \quad(3.6)$ \\
\hline \multicolumn{2}{|l|}{ Chemotherapy regimen, $\mathrm{n}(\%)$} \\
\hline FOLFIRI/cetuximab & $15(53.6)$ \\
\hline FOLFOX/cetuximab & $8(28.6)$ \\
\hline Cetuximab combined with other regimens & $5(17.8)$ \\
\hline \multicolumn{2}{|l|}{ KRAS mutation of liver metastases, $\mathrm{n}(\%)$} \\
\hline Mutated & $9(32.1)$ \\
\hline Wild-type & $19(67.9)$ \\
\hline \multicolumn{2}{|l|}{ Response after cetuximab therapy, n (\%) } \\
\hline Partial response & $12(42.9)$ \\
\hline Stable disease & $9(32.1)$ \\
\hline Progressive disease & $7(25.0)$ \\
\hline
\end{tabular}

FOLFIRI, folinic acid, 5-fluorouracil and irinotecan; FOLFOX, folinic acid, 5-fluorouracil and oxaliplatin;NA, not available, pT, pathological tumor stage; pN, pathological lymph node stage; $\mathrm{pM}$, pathological metastasis stage; $\mathrm{R}$, resection margin.

received left hemihepatectomy, 6 patients right hemihepatectomy, 18 patients partial liver resection and one patient received a liver transplantation in the context of another study. Eight patients $(28.6 \%)$ received cetuximab in combination with FOLFOX, 15 (53.6\%) in combination with FOLFIRI, and $5(17.8 \%)$ in combination with other drugs. No patient received cetuximab therapy alone. Mean duration of chemotherapy was 7.9 months. Based on RECIST criteria, 12 patients showed a partial response, nine showed stable disease, and seven showed progressive disease after treatment. All patients exhibited KRAS wild-type in primary cancer. Comparison of KRAS status (mutated vs. wild-type) in liver metastases vs. RECIST criteria (PD vs. SD vs. PR) revealed no significant difference $(P=0.260)$. Patient characteristics are shown in detail in Table I.

Protein expression analysis. Expression of EGFR protein in tumor samples did not significantly correlate with treatment response to anti-EGFR therapy according to RECIST criteria. The median EGFR/ErbB1 protein level was 2,278.8 $\mathrm{ng} / \mathrm{ml}$ (IQR 1,387.3-4,127.1 ng/ml) and was not different in groups of patients with partial response, stable disease, or progressive disease. Similarly, tumor protein levels of ErbB2 (median $348.8 \mathrm{ng} / \mathrm{ml}$, IQR 244.1-453.6 ng/ml) and ErbB3 (median $426.5 \mathrm{ng} / \mathrm{ml}$, IQR $292.3-642.4 \mathrm{ng} / \mathrm{ml}$ ) did not correlate with treatment response (Fig. 1A-C).

Expression of EGFR ligands heregulin and amphiregulin did not correlate with treatment response to anti-EGF therapy. The median heregulin protein level was $76.9 \mathrm{ng} / \mathrm{ml}$ (IQR 55-196 $\mathrm{ng} / \mathrm{ml}$ ) and the median amphiregulin protein level was 2,900.2 ng/ml (IQR 664.8-5,884.6 ng/ml). EGFR ligand protein expression did not differ between patients with partial response, stable disease, or progressive disease (Fig. 2A and B).

Survival analysis. Median overall survival of all patients was 40 months. Overall survival showed no significant difference between the three RECIST groups: median OAS PR group: 48 months [95\% CI, 36-60 months]; median OAS SD group: 30 months [95\% CI 22- 38 months]; median OAS PD group: 26 months [95\% CI, 11.5-41 months] $(\mathrm{P}=0.223)$.

Median progression free survival of all patients was 34 months. Progression free survival showed a significant difference between the three RECIST groups: median PFS PR group: 35 months [95\% CI, 21-59 months]; median PFS SD group: 16 months [95\% CI, 0-36 months]; median PFS PD group: 17 months [95\% CI, 5-38 months] $(\mathrm{P}=0.015)$. Therefore, we evaluated the differences in progression free survival between PR vs SD, PR vs PD and SD vs PD. There was a significant difference in progression free survival between the PR and the SD group $(\mathrm{P}=0.006)$, for $\mathrm{PR}$ vs $\mathrm{PD}$ respectively $\mathrm{SD}$ vs $\mathrm{PD}$ there was no significant difference in progression free survival $(\mathrm{P}=0.77$ respectively $\mathrm{P}=0.268)$ (Fig. 3).

\section{Discussion}

In this study, we determined protein levels of different EGFRs and EGFR ligands in tumor samples taken from patients with mCRC. All patients were treated with a combination chemotherapy regimen plus cetuximab. Patients were grouped into three groups based on their treatment response (determined by RECIST criteria): partial response, stable disease, and progressive disease. We observed no correlation between protein expression of EGFR and EGFR ligands in tumor tissues and treatment response. 

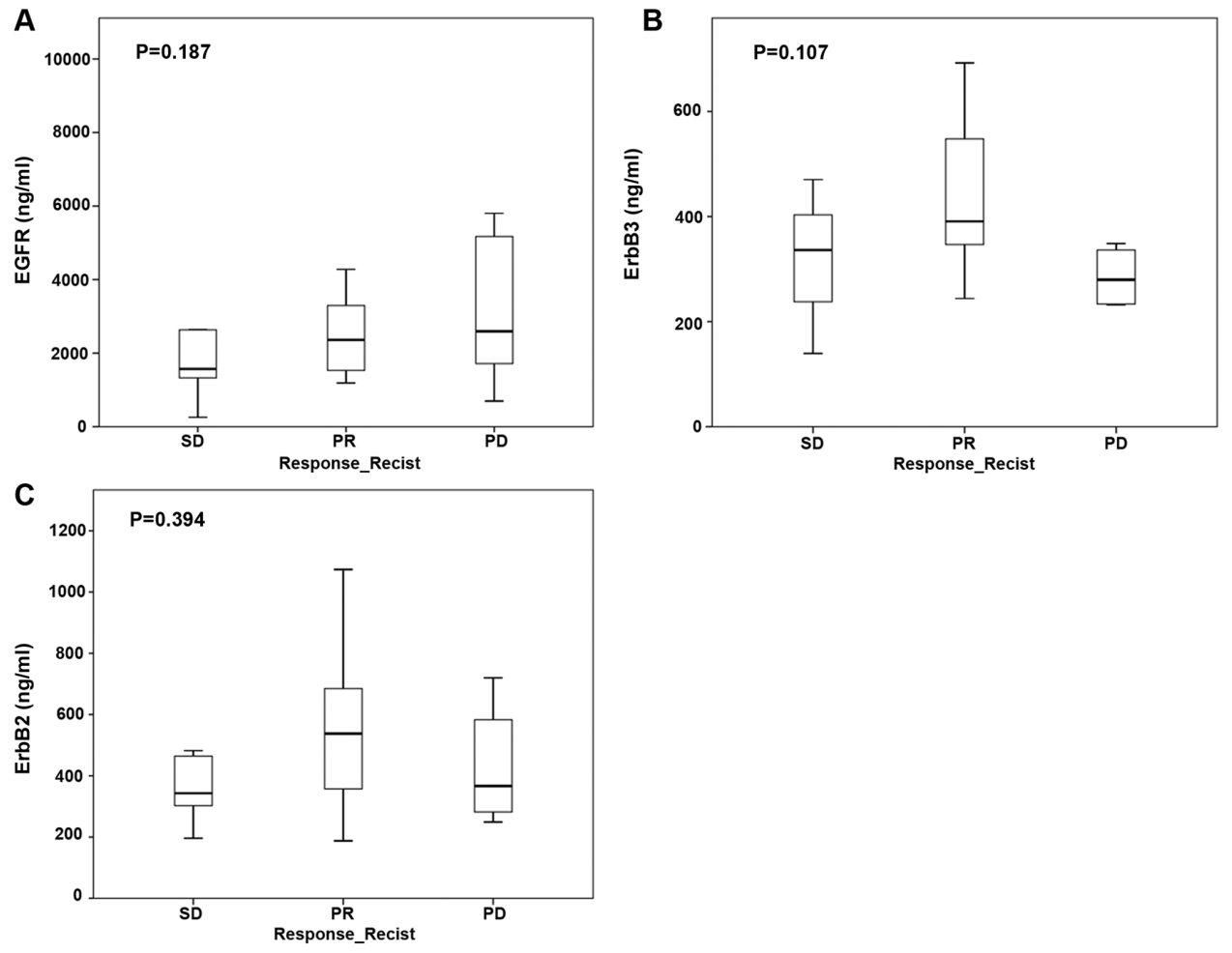

Figure 1. Association between protein levels of EGFRs and RECIST after cetuximab therapy. (A) EGFR, (B) ErbB2 and (C) ErbB3. EGFR, epidermal growth factor receptor; PD, progressive disease; PR, partial response; SD, stable disease; RECIST, response evaluation criteria in solid tumors.
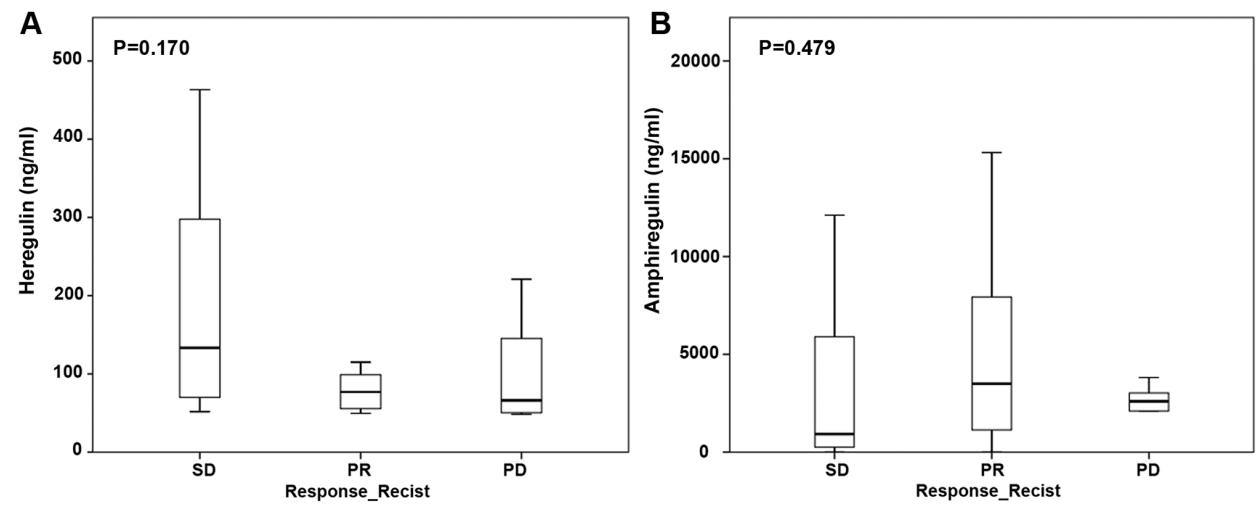

Figure 2. Association between protein levels of epidermal growth factor receptor ligands and RECIST after cetuximab therapy. (A) Heregulin and (B) amphiregulin. PD, progressive disease; PR, partial response; SD, stable disease; RECIST, response evaluation criteria in solid tumors.
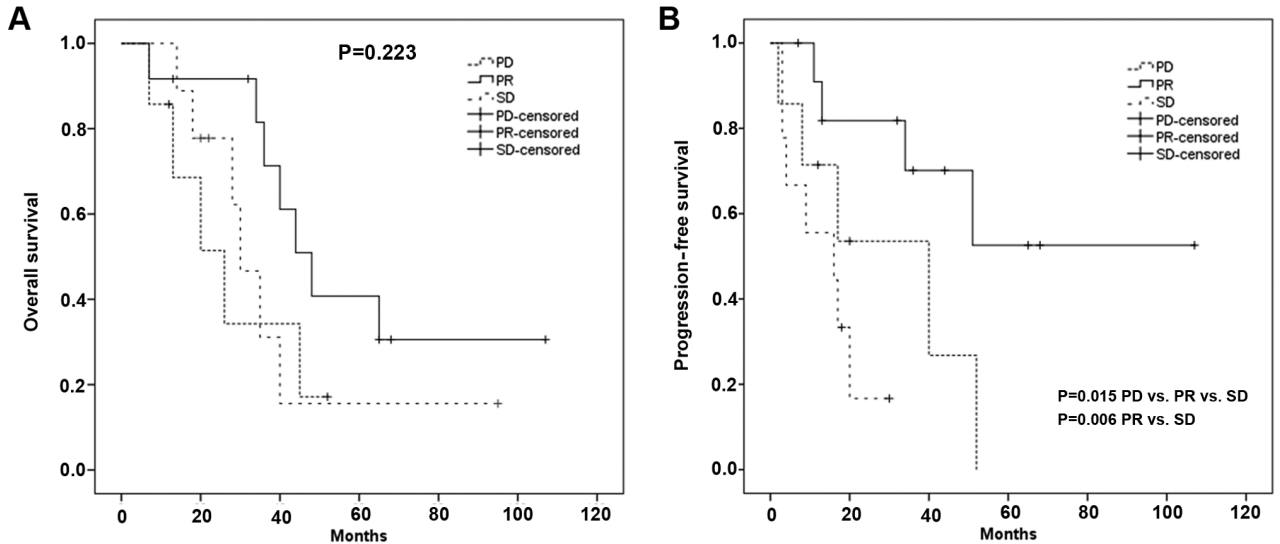

Figure 3. Association between overall survival or progression-free survival with RECIST after cetuximab therapy. (A) Overall survival and (B) progression-free survival. PD, progressive disease; PR, partial response; SD, stable disease. 
The EGF signaling pathway comprises 13 ligands. Interactions between the four known EGFRs and their ligands are remarkably complex. These interactions have been analyzed using different techniques, including immunohistochemistry, real-time PCR, fluorescence in situ hybridization (FISH), and ELISA, which differ in reliability and sensitivity. Consequently, reported EGFR and EGFR ligand expression rates vary a lot in colorectal cancer specimens in the published literature. Differences between RNA and protein expression due to posttranscriptional alterations should also be considered $(22,23)$.

Approximately $60-85 \%$ of primary colorectal cancer tissues overexpress EGFR $(24,25)$. We expected ErbB1 to be overexpressed in responding patients, but we observed no significant associations between ErbB1 expression and treatment response. This finding is in line with the results of Italiano et al (26). Others have described varying associations between EGFR expression and response to treatment and/or survival (27-29).

Several studies have examined EGFR and EGFR ligand expression and have described associations between these expression levels and response to cetuximab $(20,23,30-51)$. However, for the reasons mentioned above, these results are conflicting. The mRNA expression reported in some studies may not reflect the expression of corresponding proteins that would compete with cetuximab for EGFR binding in tumor cells.

Although anti-EGFR therapy has proven to be beneficial in KRAS wild-type advanced colorectal cancer (52), results are contradictory and underlying mechanisms are not fully understood. Some patients with selected KRAS mutations have responded to anti-EGFR therapy (53). Possible reasons could be the heterogeneity of KRAS mutations in different primary tumors and metastases (22). Furthermore, other factors may influence the therapeutic response, such as the percentage of viable tumor cells and the tumor microenvironment, which plays a pivotal role in tumor progression (54). The FOCUS-4 study has shown that combined inhibition of EGFR, ErbB2/Her2, and ErbB3/Her3 does not improve the outcome in patients with advanced colorectal cancer expressing wild-type KRAS, NRAS, B rat fibrosarcoma, and PIK3CA, so the study was closed after the first interim analysis (55).

Some limitations of the study have to be named. First limitation is the small sample size of patients included into the study. Second the retrospective study design. Third there might be a bias because of the higher frequency of male patients in the study, which was a random side effect because study patients were selected due to their received chemotherapy regime containing cetuximab regardless their sex.

Because of some unclear aspects further studies on this topic are necessary investigating RNA as well as protein level of EGF receptors and EGFR ligands to assess posttranscriptional differences and to evaluate the varying associations between EGFR expression and response to treatment and/or survival. Furthermore, it is needed to examine why selected KRAS mutations still respond to anti-EGFR therapy and to assess the influence and heterogeneity of the expressional differences in the viable tumor cells and the tumor microenvironment in order to improve the personalized treatment of patients with anti-EGF agents.

\section{Acknowledgements}

Not applicable.

\section{Funding}

FK was funded by the Olympia-Morata Postdoctoral Fellowship of the Medical Faculty of the University of Heidelberg (Heidelberg, Germany).

\section{Availability of data and materials}

The datasets used and/or analyzed during the current study are available from the corresponding author on reasonable request.

\section{Authors' contributions}

FK, MS, FB, MH, AM and YK contributed to the study design. FK, MS, EK, OG, MH and YK collected the data. FK, MS, OG, $\mathrm{MH}$ and $\mathrm{YK}$ assessed and confirmed the authenticity of all the raw data. FK, MS, EK, OG, FB, MH, AM and YK contributed to data analysis. FK, MS and YK drafted the manuscript, and MS, EK, OG, FB, MH, AM and YK reviewed the manuscript. All authors read and approved the final manuscript.

\section{Ethics approval and consent to participate}

The study was conducted ethically in accordance with the Declaration of Helsinki and the appropriate guidelines for human studies. The study was approved by the Ethics Committee of the University of Heidelberg (Heidelberg, Germany; approval no. S-168/2008) and written informed consent was obtained from each patient.

\section{Patient consent for publication}

Not applicable.

\section{Competing interests}

The authors declare that they have no competing interests.

\section{References}

1. Soerjomataram I, Lortet-Tieulent J, Parkin DM, Ferlay J, Mathers C, Forman D and Bray F: Global burden of cancer in 2008: A systematic analysis of disability-adjusted life-years in 12 world regions. Lancet 380: 1840-1850, 2012.

2. Douillard JY, Oliner KS, Siena S, Tabernero J, Burkes R, Barugel M, Humblet Y, Bodoky G, Cunningham D, Jassem J, et al: Panitumumab-FOLFOX4 treatment and RAS mutations in colorectal cancer. N Engl J Med 369: 1023-1034, 2013.

3. Mody K, Baldeo C and Bekaii-Saab T: Antiangiogenic Therapy in Colorectal Cancer. Cancer J 24: 165-170, 2018.

4. Van Cutsem E, Köhne CH, Hitre E, Zaluski J, Chang Chien CR, Makhson A, D'Haens G, Pintér T, Lim R, Bodoky G, et al: Cetuximab and chemotherapy as initial treatment for metastatic colorectal cancer. N Engl J Med 360: 1408-1417, 2009.

5. Misale S, Di Nicolantonio F, Sartore-Bianchi A, Siena S and Bardelli A: Resistance to anti-EGFR therapy in colorectal cancer: From heterogeneity to convergent evolution. Cancer Discov 4: 1269-1280, 2014.

6. Ferrara N, Hillan KJ and Novotny W: Bevacizumab (Avastin), a humanized anti-VEGF monoclonal antibody for cancer therapy. Biochem Biophys Res Commun 333: 328-335, 2005. 
7. Itatani Y, Kawada K, Yamamoto T and Sakai Y: Resistance to Anti-Angiogenic Therapy in Cancer-Alterations to Anti-VEGF Pathway. Int J Mol Sci 19: 1232, 2018.

8. McCormack PL and Keam SJ: Bevacizumab: A review of its use in metastatic colorectal cancer. Drugs 68: 487-506, 2008

9. Van Cutsem E, Cervantes A, Nordlinger B, Arnold D anD group EGW; ESMO Guidelines Working Group: Metastatic colorectal cancer: ESMO Clinical Practice Guidelines for diagnosis, treatment and follow-up. Ann Oncol 25 (Suppl 3): iiil-iii9, 2014.

10. Yarden Y: The EGFR family and its ligands in human cancer signalling mechanisms and therapeutic opportunities. Eur J Cancer 37 (Suppl 4): S3-S8, 2001.

11. Olayioye MA, Neve RM, Lane HA and Hynes NE: The ErbB signaling network: Receptor heterodimerization in development and cancer. EMBO J 19: 3159-3167, 2000.

12. Yamaoka T, Ohba M and Ohmori T: Molecular-Targeted Therapies for Epidermal Growth Factor Receptor and Its Resistance Mechanisms. Int J Mol Sci 18: 2420, 2017.

13. Petrelli F, Borgonovo K, Cabiddu M, Ghilardi M and Barni S: Cetuximab and panitumumab in KRAS wild-type colorectal cancer: A meta-analysis. Int J Colorectal Dis 26: 823-833, 2011.

14. Rizzo S, Bronte G, Fanale D, Corsini L, Silvestris N, Santini D, Gulotta G, Bazan V, Gebbia N, Fulfaro F, et al: Prognostic vs predictive molecular biomarkers in colorectal cancer: Is KRAS and BRAF wild type status required for anti-EGFR therapy? Cancer Treat Rev 36 (Suppl 3): S56-S61, 2010.

15. Karapetis CS, Khambata-Ford S, Jonker DJ, O'Callaghan CJ, Tu D, Tebbutt NC, Simes RJ, Chalchal H, Shapiro JD, Robitaille $\mathrm{S}$, et al: K-ras mutations and benefit from cetuximab in advanced colorectal cancer. N Engl J Med 359: 1757-1765, 2008

16. Misale S, Yaeger R, Hobor S, Scala E, Janakiraman M, Liska D, Valtorta E, Schiavo R, Buscarino M, Siravegna G, et al: Emergence of KRAS mutations and acquired resistance to anti-EGFR therapy in colorectal cancer. Nature 486: 532-536, 2012.

17. Van Cutsem E, Lenz HJ, Köhne CH, Heinemann V, Tejpar S, Melezínek I, Beier F, Stroh C, Rougier P, van Krieken JH, et al: Fluorouracil, leucovorin, and irinotecan plus cetuximab treatment and RAS mutations in colorectal cancer. J Clin Oncol 33: 692-700, 2015.

18. Jones C, Taylor MA and McWilliams B: The role of cetuximab as first-line treatment of colorectal liver metastases. HPB (Oxford) 15: 11-17, 2013.

19. Saltz LB, Lenz HJ, Kindler HL, Hochster HS, Wadler S, Hoff PM, Kemeny NE, Hollywood EM, Gonen M, Quinones M, et al: Randomized phase II trial of cetuximab, bevacizumab, and irinotecan compared with cetuximab and bevacizumab alone in irinotecan-refractory colorectal cancer: The BOND-2 study. J Clin Oncol 25: 4557-4561, 2007.

20. Jacobs B, De Roock W, Piessevaux H, Van Oirbeek R, Biesmans B, De Schutter J, Fieuws S, Vandesompele J, Peeters M, Van Laethem JL, et al: Amphiregulin and epiregulin mRNA expression in primary tumors predicts outcome in metastatic colorectal cancer treated with cetuximab. J Clin Oncol 27: 5068-5074, 2009.

21. Eisenhauer EA, Therasse P, Bogaerts J, Schwartz LH, Sargent D, Ford R, Dancey J, Arbuck S, Gwyther S, Mooney M, et al: New response evaluation criteria in solid tumours: Revised RECIST guideline (version 1.1). Eur J Cancer 45: 228-247, 2009.

22. Roskoski R Jr: The ErbB/HER family of protein-tyrosine kinases and cancer. Pharmacol Res 79: 34-74, 2014

23. Valtorta E, Martino C, Sartore-Bianchi A, Penaullt-Llorca F, Viale G, Risio M, Rugge M, Grigioni W, Bencardino K, Lonardi S, et al: Assessment of a HER2 scoring system for colorectal cancer: results from a validation study. Mod Pathol 28 : 1481-1491, 2015.

24. Cunningham D, Humblet Y, Siena S, Khayat D, Bleiberg H, Santoro A, Bets D, Mueser M, Harstrick A, Verslype C, et al: Cetuximab monotherapy and cetuximab plus irinotecan in irinotecan-refractory metastatic colorectal cancer. N Engl J Med 351: 337-345, 2004

25. Porebska I, Harlozińska A and Bojarowski T: Expression of the tyrosine kinase activity growth factor receptors (EGFR, ERB B2, ERB B3) in colorectal adenocarcinomas and adenomas. Tumour Biol 21: 105-115, 2000.

26. Italiano A, Follana P, Caroli FX, Badetti JL, Benchimol D, Garnier G, Gugenheim J, Haudebourg J, Keslair F, Lesbats G, et al Cetuximab shows activity in colorectal cancer patients with tumors for which FISH analysis does not detect an increase in EGFR gene copy number. Ann Surg Oncol 15: 649-654, 2008.
27. Uhlyarik A, Piurko V,Papai Z, Raso E, Lahm E, Kiss E, Sikter M, Vachaja J, Kenessey I and Timar J: EGFR Protein Expression in KRAS Wild-Type Metastatic Colorectal Cancer Is Another Negative Predictive Factor of the Cetuximab Therapy. Cancers (Basel) 12: 614, 2020.

28. Laurent-Puig P, Cayre A, Manceau G, Buc E, Bachet JB, Lecomte T, Rougier P, Lievre A, Landi B, Boige V, et al: Analysis of PTEN, BRAF, and EGFR status in determining benefit from cetuximab therapy in wild-type KRAS metastatic colon cancer. J Clin Oncol 27: 5924-5930, 2009.

29. Personeni N, Fieuws S, Piessevaux H, De Hertogh G, De Schutter J, Biesmans B, De Roock W, Capoen A, Debiec-Rychter M, Van Laethem JL, et al: Clinical usefulness of EGFR gene copy number as a predictive marker in colorectal cancer patients treated with cetuximab: A fluorescent in situ hybridization study. Clin Cancer Res 14: 5869-5876, 2008.

30. Nagaoka T, Kitaura K, Miyata Y, Kumagai K, Kaneda G, Kanazawa H, Suzuki S, Hamada Y and Suzuki R: Downregulation of epidermal growth factor receptor family receptors and ligands in a mutant K-ras group of patients with colorectal cancer. Mol Med Rep 13: 3514-3520, 2016.

31. Park DI, Kang MS, Oh SJ, Kim HJ, Cho YK, Sohn CI, Jeon WK, Kim BI, Han WK, Kim H, et al: HER-2/neu overexpression is an independent prognostic factor in colorectal cancer. Int J Colorectal Dis 22: 491-497, 2007.

32. Conradi LC, Styczen H, Sprenger T, Wolff HA, Rödel C, Nietert M, Homayounfar K, Gaedcke J, Kitz J, Talaulicar R, et al: Frequency of HER-2 positivity in rectal cancer and prognosis. Am J Surg Pathol 37: 522-531, 2013.

33. Gharib E, Salmanipour R, Nazemalhosseini Mojarad E, Yaghoob Taleghani M, Sarlak S, Malekzade-Moghani M, Nasrabadi PN, Meiary MA, Asadzadeh Aghdaei H and Zali MR: $\mathrm{HER}^{+}{ }^{+}$CRC patients with exon $20 \mathrm{R} 784 \mathrm{G}$ substitution mutation do not respond to the cetuximab therapy. J Cell Physiol 234: 13137-13144, 2019.

34. Aurisicchio L, Marra E, Roscilli G, Mancini R and Ciliberto G: The promise of anti-ErbB3 monoclonals as new cancer therapeutics. Oncotarget 3: 744-758, 2012.

35. Beji A, Horst D, Engel J, Kirchner T and Ullrich A: Toward the prognostic significance and therapeutic potential of HER3 receptor tyrosine kinase in human colon cancer. Clin Cancer Res 18: 956-968, 2012

36. Scartozzi M, Giampieri R, Maccaroni E, Mandolesi A, Giustini L, Silva R, Zaniboni A, Biscotti T, Biagetti S, Galizia E, et al: Analysis of HER-3, insulin growth factor-1, nuclear factor- $\kappa B$ and epidermal growth factor receptor gene copy number in the prediction of clinical outcome for K-RAS wild-type colorectal cancer patients receiving irinotecan-cetuximab. Ann Oncol 23: $1706-1712,2012$

37. Lédel F, Hallström M, Ragnhammar P, Öhrling K and Edler D: HER3 expression in patients with primary colorectal cancer and corresponding lymph node metastases related to clinical outcome. Eur J Cancer 50: 656-662, 2014.

38. Cushman SM, Jiang C, Hatch AJ, Shterev I, Sibley AB, Niedzwiecki D, Venook AP, Owzar K. Hurwitz HI and Nixon AB: Gene expression markers of efficacy and resistance to cetuximab treatment in metastatic colorectal cancer: results from CALGB 80203 (Alliance). Clin Cancer Res 21: 1078-1086, 2015.

39. Stahler A, Heinemann V, Neumann J, Crispin A, Schalhorn A, Stintzing S, Giessen-Jung C, Fischer von Weikersthal L, Vehling-Kaiser U, Stauch M, et al: Prevalence and influence on outcome of HER2/neu, HER3 and NRG1 expression in patients with metastatic colorectal cancer. Anticancer Drugs 28: 717-722, 2017.

40. Busser B, Sancey L, Brambilla E, Coll JL and Hurbin A: The multiple roles of amphiregulin in human cancer. Biochim Biophys Acta 1816: 119-131, 2011.

41. Zvibel I, Brill S, Halpern Z and Papa M: Amphiregulin and hepatocyte-derived extracellular matrix regulate proliferation and autocrine growth factor expression in colon cancer cell lines of varying liver-colonizing capability. J Cell Biochem 76: 332-340, 1999.

42. Jing C, Jin YH, You Z, Qiong Q and Jun Z: Prognostic value of amphiregulin and epiregulin mRNA expression in metastatic colorectal cancer patients. Oncotarget 7: 55890-55899, 2016.

43. Lo Nigro C, Ricci V, Vivenza D, Granetto C, Fabozzi T, Miraglio E and Merlano MC: Prognostic and predictive biomarkers in metastatic colorectal cancer anti-EGFR therapy. World J Gastroenterol 22: 6944-6954, 2016. 
44. Nishimura T, Andoh A, Inatomi O, Shioya M, Yagi Y, Tsujikawa T and Fujiyama Y: Amphiregulin and epiregulin expression in neoplastic and inflammatory lesions in the colon. Oncol Rep 19: 105-110, 2008

45. Yamada M, Ichikawa Y, Yamagishi S, Momiyama N, Ota M, Fujii S, Tanaka K, Togo S, Ohki S and Shimada H: Amphiregulin is a promising prognostic marker for liver metastases of colorectal cancer. Clin Cancer Res 14: 2351-2356, 2008.

46. Seligmann JF, Elliott F, Richman SD, Jacobs B, Hemmings G Brown S, Barrett JH, Tejpar S, Quirke P and Seymour MT: Combined Epiregulin and Amphiregulin Expression Levels as a Predictive Biomarker for Panitumumab Therapy Benefit or Lack of Benefit in Patients With RAS Wild-Type Advanced Colorectal Cancer. JAMA Oncol 2: 633-642, 2016.

47. Yoshida M, Shimura T, Sato M, Ebi M, Nakazawa T, Takeyama $\mathrm{H}$ and Joh T: A novel predictive strategy by immunohistochemical analysis of four EGFR ligands in metastatic colorectal cancer treated with anti-EGFR antibodies. J Cancer Res Clin Oncol 139: 367-378, 2013

48. Sebio A, Páez D, Salazar J, Berenguer-Llergo A, Paré-Brunet L, Lasa A, Del Río E, Tobeña M, Martín-Richard M, Baiget M, et al: Intergenic polymorphisms in the amphiregulin gene region as biomarkers in metastatic colorectal cancer patients treated with anti-EGFR plus irinotecan. Pharmacogenomics J 14: 256-262, 2014.

49. Breuleux M: Role of heregulin in human cancer. Cell Mol Life Sci 64: 2358-2377, 2007.
50. Khurana A, Gonzalez-Guerrico A and Lupu R: Heregulin in breast cancer: Old story, new paradigm. Curr Pharm Des 20: 4874-4878, 2014.

51. Yonesaka K, Zejnullahu K, Okamoto I, Satoh T, Cappuzzo F, Souglakos J, Ercan D, Rogers A, Roncalli M, Takeda M, et al: Activation of ERBB2 signaling causes resistance to the EGFR-directed therapeutic antibody cetuximab. Sci Transl Med 3: 99ra86, 2011.

52. Tsilimigras DI, Ntanasis-Stathopoulos I, Bagante F, Moris D, Cloyd J, Spartalis E and Pawlik TM: Clinical significance and prognostic relevance of KRAS, BRAF, PI3K and TP53 genetic mutation analysis for resectable and unresectable colorectal liver metastases: A systematic review of the current evidence. Surg Oncol 27: 280-288, 2018.

53. De Roock W, Jonker DJ, Di Nicolantonio F, Sartore-Bianchi A, Tu D, Siena S, Lamba S, Arena S, Frattini M, Piessevaux H, et al: Association of KRAS p.G13D mutation with outcome in patients with chemotherapy-refractory metastatic colorectal cancer treated with cetuximab. JAMA 304: 1812-1820, 2010.

54. Pietras K and Ostman A: Hallmarks of cancer: Interactions with the tumor stroma. Exp Cell Res 316: 1324-1331, 2010.

55. Adams R, Brown E, Brown L, Butler R, Falk S, Fisher D, Kaplan R, Quirke P, Richman S, Samuel L, et al; FOCUS4 Trial Investigators: Inhibition of EGFR, HER2, and HER3 signalling in patients with colorectal cancer wild-type for BRAF, PIK3CA, KRAS, and NRAS (FOCUS4-D): A phase 2-3 randomised trial. Lancet Gastroenterol Hepatol 3: 162-171, 2018. 